\title{
CARBOXYPEPTIDASE Y CATALYZED TRANSPEPTIDATION AND CONDENSATION REACTIONS
}

\author{
by \\ KLAUS BREDDAM, JACK T. JOHANSEN ${ }^{1)}$ and MARTIN OTTESEN \\ Department of Chemistry, Carlsberg Laboratory \\ Gamle Carlsberg Vej 10, DK-2500 Copenhagen Valby \\ ${ }^{1)}$ Present address: Carlsberg Biotechnology Ltd. A/S \\ Tagensvej 16, DK-2200 Copenhagen $\mathrm{N}$
}

Keywords: Enzymatic synthesis, transpeptidation, protein semisynthesis, insulin, carboxypeptidase $\mathrm{Y}$.

\begin{abstract}
While the action of carboxypeptidase $Y$ on peptides in the presence of an amino acid amide results in transpeptidation products where the $\mathrm{C}$-terminal amino acid residue is exchanged, side products can appear due to condensation reactions. These reactions occur when the peptide is a poor substrate for the enzyme, and hence the competing transpeptidation reaction is very slow. The B-chain of native porcine insulin is such a substrate, and in the presence of $\mathrm{H}-\mathrm{Thr}-\mathrm{NH}_{2}$ the condensation product $\left(\mathrm{Thr}-\mathrm{NH}_{2}\right)^{\mathrm{B} 31}$ insulin is formed together with the transpeptidation product des(Ala) ${ }^{330}\left(\mathrm{Thr}-\mathrm{NH}_{2}\right)^{330}$ insulin. The condensation product is only temporarily present in the reaction mixture. It disappears with time in favor of the transpeptidation product. The same reaction pattern is demonstrated for a model compound of insulin Bz-Lys-Ala-OH, and the amount of condensation product is influenced by the reaction conditions: $\mathrm{pH}$, concentration of reactants and solvents. A reaction scheme is proposed to explain the results.
\end{abstract}

\section{INTRODUCTION}

It has previously been demonstrated that CPD-Y in the presence of an amino acid derivative catalyzes transpeptidation reactions in aqueous solutions $(1,2,3)$. These reactions proceed through an acyl-enzyme intermediate and result in accumulation of a product where the C-terminal residue has been replaced by the amino acid or amino acid derivative acting as the nucleophile in the reaction. However, during attempts to increase the yield in the conversion of porcine insulin to human insulin by such a transpeptidation reaction (3) it was observed that CPD-Y simultaneously to a small extent catalyzed a condensation reaction, i.e., a peptide elongation without exchange of the C-terminal amino acid residue. In the present paper this reaction has been studied in more details and a model compound corresponding to the C-terminal segment of the B-chain of porcine insulin

Abbreviations: $\mathrm{Bz}=$ benzoyl; $\mathrm{Cbz}=$ carbobenzoxy; $\mathrm{CPD}-\mathrm{Y}=$ carboxypeptidase $\mathrm{Y} ; \mathrm{DMF}=\mathrm{N}, \mathrm{N}$-dimethylformamide; DPCC = diphenyl carbamyl chloride; TEAP = triethylammonium phosphate buffer; HPLC = high performance liquid chromatography. Since only the C-terminal of the B-chain of insulin is involved in these reactions, INS-Pro-Lys-Ala-OH is used as an abbreviation of porcine insulin. Other insulin derivatives are thus abbreviated accordingly: INS-Pro-Lys-OH $=\operatorname{des}(\mathrm{Ala}){ }^{\mathrm{B} 30}$ insulin, INS-Pro-Lys-Thr- $\mathrm{NH}_{2}=\operatorname{des}(\mathrm{Ala})^{\mathrm{B} 30}(\mathrm{Thr}-$ $\left.\mathrm{NH}_{2}\right)^{\mathrm{B} 30}$ insulin, etc. 
has been included to study the effect of reaction conditions on the formation of condensation products in the reaction mixture.

\section{MATERIALS AND METHODS}

\subsection{Materials}

CPD-Y was obtained as previously described $(3,10)$, porcine insulin was a generous gift from Nordisk Insulinlaboratorium, Denmark, through the courtesy of Dr. B. HANSEN, and L-threonine amide hydrochloride was a gift of Dr. O.H. MANSCHER. Dansyl chloride and trypsin were obtained from Sigma, USA. Chromatographic materials were products of Pharmacia, Sweden. All other reagents and solvents were analytical grade from Merck, W. Germany.

Bz-Lys-Ala-OH was prepared enzymatically via Bz-Lys-Ala-OMe in the following manner: 7 mmoles Bz-Lys-OMe and 18 mmoles H-AlaOMe $\mathrm{HCl}$ was dissolved in $33 \mathrm{ml} 60 \%$ DMF and $30 \mathrm{mg}$ DPCC-trypsin added. The reaction was performed at $\mathrm{pH} 9.5$ in a $\mathrm{pH}$ stat and resulted after $1 / 2$ hours in a coupling yield of 70\% based on HPLC analysis (see section 2.2.1). At this point the reaction was quenched by addition of $200 \mathrm{ml}$ acetonitrile and Bz-Lys-AlaOMe was isolated using the Waters preparative HPLC system operating with a reverse phase C-1 8 column. Bz-Lys-Ala-OH was prepared by incubation of Bz-Lys-Ala-OMe for 6 hours at $\mathrm{pH} 10.2$.

\subsection{Methods}

\subsubsection{Transpeptidation reactions with $B z-L y s-A l a-O H$}

Ail reactions were performed in a $\mathrm{pH}$ stat. Aliquots of the reaction mixture were diluted into acetonitrile in order to quench the reactions and analyzed by HPLC, using a Waters liquid chromatography system, consisting of a Model U6K injector and two Model 6000 pumps, a model 660 Solvent programmer, a Model 450 UV detector, a Waters Data Module and a Waters Radial Compression Module (RCM 100) with a Waters Radial Pak A (C-18 reverse phase) column. A-buffer: 50 mM-TEAP. Bbuffer: $50 \%$ acetonitrile $+50 \%$ A-buffer. The concave gradient No. 10 was used from $15 \%$ B to
$100 \% \mathrm{~B}$ in 5 minutes at a flow rate of $4 \mathrm{ml} \times \mathrm{min}^{-1}$. Products, not identifiable by chromatography of authentic samples, were collected and identified by amino acid analysis. The per cent composition could be calculated directly from the integrated peak areas, since all reactants had the same dominant chromophore (Bz-).

\subsubsection{Transpeptidation reactions with insulin}

This reaction was performed in a $\mathrm{pH}$ stat using. the following reaction conditions: $2 \mathrm{mM}-\mathrm{Zn}$-free porcine insulin, $1.5 \mathrm{M}$-guanidine hydrochloride, $0.5 \mathrm{M}-\mathrm{H}$-Thr- $\mathrm{NH}_{2}, 0.1 \mathrm{M}-\mathrm{KCl}, 2 \mathrm{mM}$-EDTA, 15 $\mu \mathrm{M}-\mathrm{CPD}-\mathrm{Y}, \mathrm{pH}$ 7.5. The time course of the reaction was followed by taking aliquots and the reaction was quenched by addition of sufficient amounts of $1 \mathrm{M}-\mathrm{HCl}$ to adjust $\mathrm{pH}$ to approximately 1.7 . The reactant composition was analyzed as previously described (3): The insulin fraction was separated from the enzyme and from low molecular weight material by chromatography on Sephadex G-50 and then further separated in three peaks by chromatography on DEAE-Sepharose CL 6B. Peak I contained INSPro-Lys-Thr-NH, INS-Pro-Lys-Thr-Thr-NH

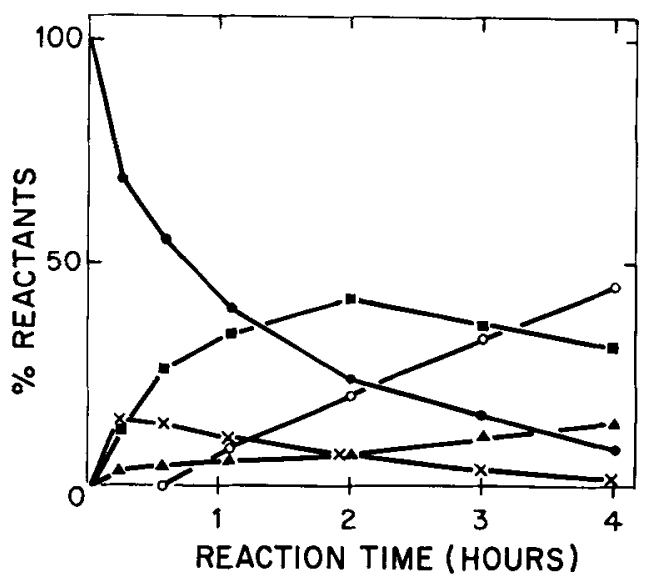

Figure 1. CPD-Y catalyzed transpeptidation using Bz-Lys-Ala-OH as acyl component and $\mathrm{H}-\mathrm{Thr}-\mathrm{NH}_{2}$ as amine component.

Conditions: $5 \mathrm{~mm}$-Bz-Lys-Ala-OH, $0.5 \mathrm{M}-\mathrm{H}-\mathrm{Thr}-$ $\mathrm{NH}_{2}, 0.1 \mathrm{M}-\mathrm{KCl}, 1 \mathrm{~mm}$-EDTA, $45 \mu \mathrm{M}$-CPD-Y, pH 6.5

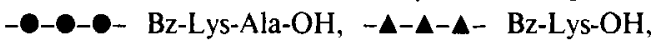

-n-m-n- Bz-Lys-Thr-NH ${ }_{2},-\mathrm{O}-\mathrm{O}-\mathrm{O}-\mathrm{Bz}-\mathrm{Lys}-\mathrm{Thr}-$ $\mathrm{OH}+\mathrm{Bz}-$ Lys-Thr-Thr-NH$H_{2},-x-x-x-$ Bz-Lys-Ala-Thr$\mathrm{NH}_{2}$. 


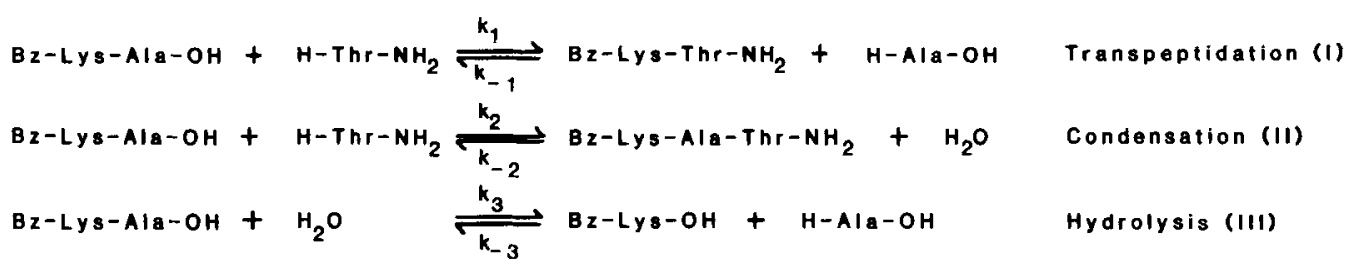

Scheme 1: Reaction courses for the action of CPD-Y on peptides in the presence of a nucleophile (H-Thr- $\left.\mathrm{NH}_{2}\right)$.

and INS-Pro-Lys-Ala-Thr-NH 2 . Peak II contained INS-Pro-Lys-OH, INS-Pro-Lys-Thr-OH, INS-Pro-Lys-Ala-OH and INS-Pro-Thr- $\mathrm{NH}_{2}$. Peak III contained various degradation products. The percentage of each reactant was determined from the relative areas of the peaks and from their amino acid composition (3), as determined after hydrolysis for 24 hours in $6 \mathrm{M}-\mathrm{HCl}$. The amount of INS-Pro-Lys-Ala-Thr- $\mathrm{NH}_{2}$ in peak I estimated in this fashion was confirmed by the amount of alanine released in digestions with CPD-Y and by HPLC analysis of the peptides produced by trypsin digestions (3).

\section{RESULTS}

The CPD-Y catalyzed transpeptidation reactions with Bz-Lys-Ala-OH, which corresponds to the C-terminal sequence of the B-chain of porcine insulin, was performed at $\mathrm{pH} 6.5$ using $\mathrm{H}-\mathrm{Thr}-\mathrm{NH}_{2}$ as nucleophile. The time course of the reaction (Figure 1) demonstrate that initially the condensation product, Bz-Lys-Ala-Thr$\mathrm{NH}_{2}$, is formed together with the hydrolysis product, Bz-Lys-OH, and the transpeptidation product, Bz-Lys-Thr- $\mathrm{NH}_{2}$. By further reaction of the transpeptidation product $\mathrm{Bz}-\mathrm{L}$ ys- $\mathrm{Thr}-\mathrm{OH}$ and $\mathrm{Bz}$-Lys-Thr-Thr- $\mathrm{NH}_{2}$ are formed. It is seen that the condensation product disappears slowly in favor of the transpeptidation product. In Scheme 1 are shown reaction pathways corresponding to the formation of these products.

The formation of the condensation product, Bz-Lys-Ala-Thr- $\mathrm{NH}_{2}$, varies with $\mathrm{pH}$ as illustrated in Table I. All the experiments listed corresponds to reaction times where about $50 \%$ of the substrate, Bz-Lys-Ala-OH, is converted. It is seen that decreasing proportions of Bz-LysAla-Thr- $\mathrm{NH}_{2}$ is formed at higher $\mathrm{pH}$ values with no condensation product at $\mathrm{pH} 8.5$.

Since the condensation reaction, as indicated in Scheme 1, reflects the equilibrium: Bz-LysAla-OH $+\mathrm{H}-\mathrm{Thr}-\mathrm{NH}_{2} \stackrel{\text { PPQ- }}{=}$ Bz-Lys-Ala-Thr$\mathrm{NH}_{2}+\mathrm{H}_{2} \mathrm{O}$, it was investigated how other changes in the reaction conditions could influence the formation of condensation product. When the reaction was performed at $2.0 \mathrm{M}-\mathrm{H}$ Thr- $\mathrm{NH}_{2}$ the percentage of Bz-Lys-Ala-Thr$\mathrm{NH}_{2}$ in the reaction mixture increased to $22 \%$ at the maximum (Figure 2) while it was only 15\% when the concentration of $\mathrm{H}-\mathrm{Thr}-\mathrm{NH}_{2}$ was 0.5 $M$ (Figure 1). Addition of $30 \%$ DMF to the

Table I.

Influence of $\mathrm{pH}$ on the composition of the reaction mixture in CPD-Y catalyzed transpeptidation using Bz-Lys-Ala-OH as acyl component.

\begin{tabular}{llccc}
\hline Reactant & pH 5.5 & pH 6.5 & pH 7.5 & pH 8.5 \\
\hline Bz-Lys-Ala-OH & 56 & 55 & 50 & 54 \\
Bz-Lys-OH & 12 & 3 & 2 & 0 \\
Bz-Lys-Thr-NH & 17 & 26 & 30 & 25 \\
Bz-Lys-Ala-Thr-NH & 15 & 14 & 6 & 0 \\
Bz-Lys-Thr-OH & 0 & 1 & 2 & 3 \\
Bz-Lys-Thr-Thr-NH & 0 & 1 & 10 & 18 \\
\hline
\end{tabular}

Reaction conditions: $5 \mathrm{~mm}$-Bz-Lys-Ala-OH, $0.5 \mathrm{M}-\mathrm{H}-\mathrm{Thr}-\mathrm{NH}_{2}, 0.1 \mathrm{M}-\mathrm{KCl}, 1 \mathrm{~mm}-\mathrm{EDTA}, 45 \mu \mathrm{M}-\mathrm{CPD}-\mathrm{Y}$. The reaction time was $90 \mathrm{~min}$ at $\mathrm{pH} 5.5,35 \mathrm{~min}$ at $\mathrm{pH} 6.5,42 \mathrm{~min}$ at $\mathrm{pH} 7.5$ and $90 \mathrm{~min}$ at $\mathrm{pH} 8.5$. 


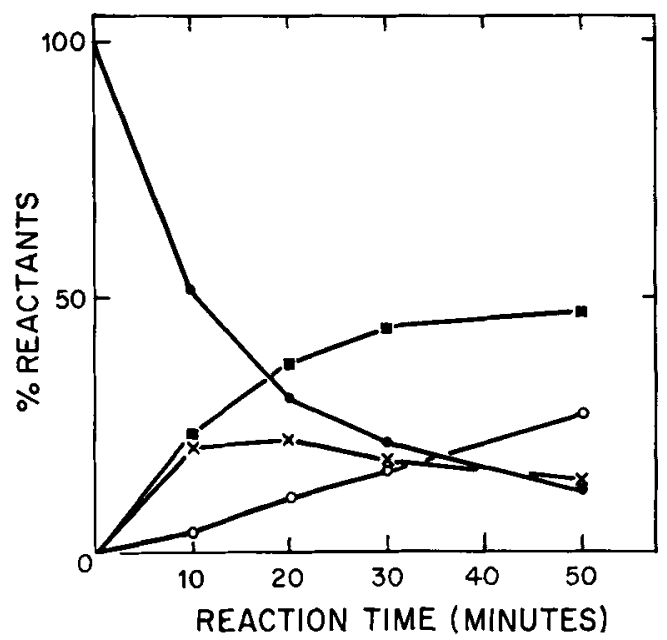

Figure 2. CPD-Y catalyzed transpeptidation reaction using Bz-Lys-Ala-OH as acyl component and $\mathrm{H}-\mathrm{Thr}$ $\mathrm{NH}_{2}$ as amine component.

Conditions: $5 \mathrm{~mm}$-Bz-Lys-Ala-OH, $2.0 \mathrm{M}-\mathrm{H}-\mathrm{Thr}-$ $\mathrm{NH}_{2}, 0.1 \mathrm{~m}-\mathrm{KCl}, 1 \mathrm{~mm}-\mathrm{EDTA}, 78 \mu \mathrm{m}-\mathrm{CPD}-\mathrm{Y}, \mathrm{pH}$ 6.5. Symbols: see Figure 1.

reaction mixture, which decreased the polarity of the reaction medium, increased the content of Bz-Lys-Ala-Thr- $\mathrm{NH}_{2}$ to $32 \%$ (Figure 3).

With porcine insulin, transpeptidation reactions were performed analogously to the reac-

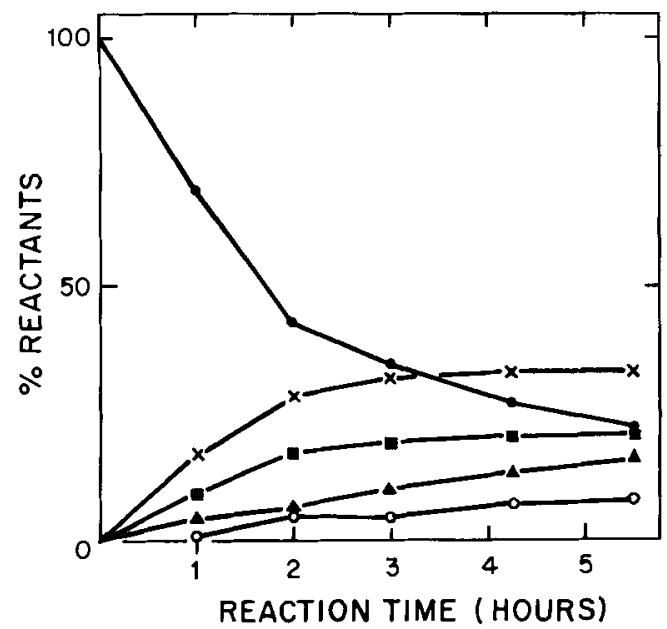

Figure 3. CPD-Y catalyzed transpeptidation reaction using Bz-Lys-Ala-OH as acyl component and $\mathrm{H}-\mathrm{Thr}-$ $\mathrm{NH}_{2}$ as amine component in the presence of DMF.

Conditions: $5 \mathrm{~mm}$-Bz-Lys-Ala-OH, $2.0 \mathrm{M}-\mathrm{H}-\mathrm{Th}$ $\mathrm{NH}_{2}, 30 \%$ DMF (v/v), $0.1 \mathrm{M}-\mathrm{KCl}, 1$ mм-EDTA, 150 $\mu \mathrm{M}-\mathrm{CPD}-\mathrm{Y}, \mathrm{pH}$ 6.5. Symbols: see Figure 1.

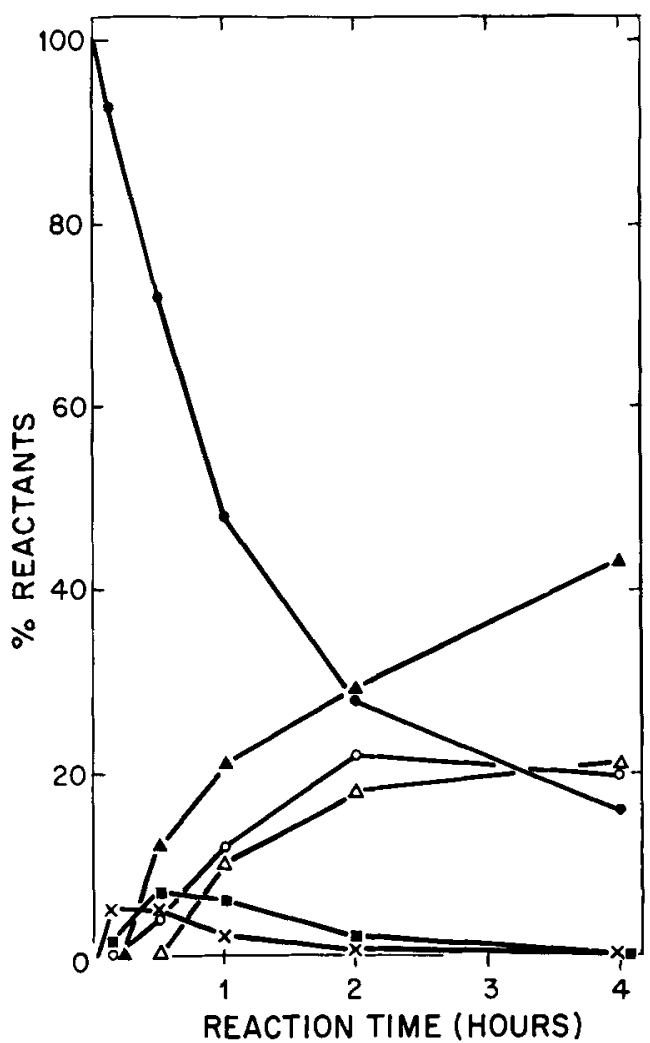

Figure 4. CPD-Y catalyzed transpeptidation using porcine insulin (INS-Pro-Lys-Ala-OH) as acyl component and $\mathrm{H}-\mathrm{Thr}-\mathrm{NH}_{2}$ as amine component.

Reaction conditions: 2 mm-porcine insulin, $1.5 \mathrm{M}$-guanidine hydrochloride, $0.5 \mathrm{M}-\mathrm{H}-\mathrm{Thr}-\mathrm{NH}_{2}$, $0.1 \mathrm{M}-\mathrm{KCl}, 1 \mathrm{~mm}-\mathrm{EDTA}, 15 \mu \mathrm{M}-\mathrm{CPD}-\mathrm{Y}, \mathrm{pH} 7.5$.

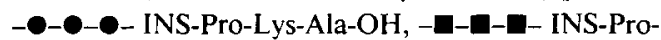
Lys-Thr-NH,$\quad-\mathrm{O}-\mathrm{O}-\mathrm{O}-$ INS-Pro-Lys-Thr-Thr$\mathrm{NH}_{2},-x-x-x$ - INS-Pro-Lys-Ala-Thr-NH $\mathrm{NH}_{2}, \Delta-\Delta-\Delta-$ INS-Pro-Lys-Thr-OH, -A-A-A- INS-Pro-Lys-OH and reaction products hereof.

tions with Bz-Lys-Ala-OH. The formation of the expected condensation product, INS-Pro-LysAla-Thr- $\mathrm{NH}_{2}$, was confirmed by identification of the peptides produced by trypsin digestions (3). Trypsin, cleaving on the carbonyl side of the penultimate lysyl residue, produces the peptides H-Ala-Thr-NH ${ }_{2}, \mathrm{H}-\mathrm{Thr}-\mathrm{Thr}-\mathrm{NH}_{2}$ and H-Thr$\mathrm{NH}_{2}$ from the combined insulin derivatives in Peak I. H-Ala-Thr- $\mathrm{NH}_{2}$ was present in amounts corresponding to those estimated from the amino acid composition and CPD-Y digestions of Peak I. The reaction pattern (Figure 4) is very similar to the pattern observed with Bz-Lys-Ala- 
$\mathrm{OH}$ : the condensation product, INS-Pro-LysAla-Thr- $\mathrm{NH}_{2}$, which initially is the dominating product, disappears with time in favor of the transpeptidation product, INS-Pro-Lys-Thr$\mathrm{NH}_{2}$, and the hydrolysis product, INS-Pro-Lys$\mathrm{OH}$. Similar to the results with Bz-Lys-Ala-OH, the transpeptidation product of porcine insulin reacts further to give INS-Pro-Lys-Thr-OH (hydrolysis) and INS-Pro-Lys-Thr-Thr- $\mathrm{NH}_{2}$ (transpeptidation). The hydrolysis product also reacts further to give various hydrolysis and transpeptidation products.

\section{DISCUSSION}

Scheme I outlines how a peptide substrate of CPD-Y in the presence of an amino acid amide can act as acyl component in both transpeptidation (Reaction I), condensation (Reaction II) and in hydrolysis reactions (Reaction III). The rate constants of these competing reactions control the reactant composition and earlier CPD-Y catalyzed transpeptidation studies, where the reaction was quenched before final equilibrium was obtained, indicated that Reactions I and III were the dominant reactions and much faster than Reaction II $(1,2)$. Actually, significant amounts of condensation product can only be expected to be formed when $k_{1}$ and $k_{3}$ are lower than or of the same order as $k_{2}$. The results in the present study indicates that Bz-Lys-Ala-OH, presumably due to the presence of the positive charge on the lysyl residue in the penultimate position (4), behaves as a poor substrate with accumulation of the condensation product.

In order to understand the formation of the condensation product and its disappearance with time it is necessary first to evaluate the magnitude of the equilibrium constant of Reaction II. Condensation reactions of this type have previously been shown to exhibit equilibrium constants $\mathrm{K}_{\mathrm{syn}}$ of $0.3-0.5 \mathrm{M}^{-1}(5,8,12)$. If reactions I and III are disregarded a $\mathrm{K}_{\text {syn }}$ of 0.5 would predict equilibrium concentrations of Bz-Lys-Ala-Thr- $\mathrm{NH}_{2}$ of $1.25 \mathrm{~mm}$ and $2.5 \mathrm{~mm}$ at the high concentrations of amine component employed in the experiments listed in Figures 1 and 2 , respectively. The maximum concentrations of Bz-Lys-Ala-Thr- $\mathrm{NH}_{2}$ found in the reaction mixtures were $0.7 \mathrm{mM}$ and $1.1 \mathrm{mM}$, respecti- vely. These values appear reasonable when it is taken into account that Reactions I and III occur simultaneously with Reaction II in such a way that the equilibrium concentration can never be reached at any time during the course of the reaction. Since Reactions I and III, as emphasized in the excellent review by J. FRUTON (6), have equilibrium constants which greatly exceed unity, the products of these reactions, Bz-LysThr- $\mathrm{NH}_{2}$ and Bz-Lys-OH, are energetically more favorable than Bz-Lys-Ala-Thr- $\mathrm{NH}_{2}$. Consistent with this, the condensation reaction is seen to be displaced in direction of hydrolysis as the amount of Bz-Lys-Ala-OH in the reaction mixture decreases. Bz-Lys-Ala-OH is therefore ultimately converted to Bz-Lys-OH and Bz-LysThr $-\mathrm{NH}_{2}$. The latter substance reacts further to yield Bz-Lys-Thr-OH and Bz-Lys-Thr-Thr$\mathrm{NH}_{2}$.

The $\mathrm{pH}$ and the polarity of the reaction medium influence the product composition in the early stages of the reaction, signifying changes in the relative magnitudes of $k_{1}, k_{2}$ and $\mathrm{k}_{3}$. Increasing the $\mathrm{pH}$ of the reaction mixture above 5.5 results in a decrease in the ratio of $k_{2} / k_{1}$. Since the peptidase activity ofCPD-Y does not increase with $\mathrm{pH}(10)$ this probably reflects a $\mathrm{pH}$ dependence of $\mathrm{k}_{2}$ rather than $k_{1}$. In the presence of DMF $k_{2}$ is significantly higher than $\mathrm{k}_{1}$ and $\mathrm{k}_{3}$, possibly because the peptidase activity of CPD-Y is inhibited by DMF (7). In the later stages of the reaction the amount of Bz-Lys-Ala$\mathrm{Thr}-\mathrm{NH}_{2}$ accumulated in the reaction mixture is influenced by the equilibrium constant of Reaction II which in other systems has been shown to vary with $\mathrm{pH}(8)$ and increase drastically in the presence of organic solvents $(8,9,11)$.

The reaction pattern observed when porcine insulin was used as substrate in aqueous solution was similar to the reaction pattern for Bz-LysAla-OH suggesting that the latter is a relevant model for the C-terminal segment of the B-chain of porcine insulin. However, when half of the Bz-Lys-Ala-OH had been converted at pH 7.5, the reaction mixture contained $6 \% \mathrm{Bz}-\mathrm{Lys}$-Ala$\mathrm{Thr}-\mathrm{NH}_{2}$ while with porcine insulin under analogous conditions the reaction mixture only contained $2 \%$ INS-Pro-Lys-Ala-Thr- $\mathrm{NH}_{2}$. These results suggest insulin to be a better substrate of CPD-Y than Bz-Lys-Ala-OH. 
For the future use of CPD-Y in transpeptidation reactions it is important to be aware of the possibility that side products may be formed due to condensation reactions. Attempts can be made to minimize the formation of these products by decreasing the concentration of reactants as far as possible and by performing the reaction under conditions where the rate of transpeptidation is maximal. Other side products can be formed as well since the products of the reaction may serve as substrates of the enzyme under the conditions of coupling.

\section{ACKNOWLEDGEMENTS}

The excellent technical assistance of Mss. PIA BREDDAM and IRENE SIMONSEN is gratefully acknowledged. Dr. A. ANDERSEN is acknowledged for his help preparing Bz-Lys-Ala-OH and Dr. O.H. MANSCHER for preparing H-Thr$\mathrm{NH}_{2} \cdot \mathrm{HCl}$.

\section{REFERENCES}

1. BREDdAM, K., F. WidMER \& J.T. Johansen: Carboxypeptidase $\mathrm{Y}$ catalyzed transpeptidations and enzymatic peptide synthesis. Carlsberg Res. Commun. 45, 237-247 (1980)

2. Breddam, K., F. Widmer \& J.T. Johansen: Carboxypeptidase $\mathrm{Y}$ catalyzed C-terminal modifications of peptides. Carlsberg Res. Commun. 46, $121-128,(1981)$
3. BREddam, K., F. Widmer \& J.T. Johansen: Carboxypeptidase $\mathrm{Y}$ catalyzed $\mathrm{C}$-terminal modification in the B-chain of porcine insulin. Carlsberg Res. Commun. 46, 361-372 (1981)

4. BREDDAM, K: Modification of the single sulfhydryl group of carboxypeptidase $Y$ with mercurials. Influence on enzyme specificity. Carlsberg Res. Commun 48, 9-19 (1983)

5. Dobry, A., J.S. Fruton \& J.M. Sturtevant: Thermodynamics of hydrolysis of peptide bonds. J. Biol. Chem. 195, 149-154 (1952)

6. Fruton, J.S.: Proteinase-catalyzed synthesis of peptide bonds. In: Adv. Enzymol., A. Meister ed., John Wiley, New York, pp. 239-306 (1982)

7. Hayashi, R., Y. Bai \& T. HATA: Kinetic studies of carboxypeptidase Y. I. Kinetic parameters for the hydrolysis of synthetic substrates. J. Biochem. (Tokyo) 77, 69-79 (1975)

8. HomandberG、G.A., J.A. Mattis \& M. LasKOWSKI: Synthesis of peptide bonds by proteinases. Addition of organic cosolvents shifts peptide bond equilibria toward synthesis. Biochemistry 17 , 5220-5227 (1978)

9. HomandberG, G.A.\& M. Laskowski: Enzymatic resynthesis of the hydrolyzed peptide bond(s) in ribonuclease S. Biochemistry 18, 586-592 (1979)

10. Johansen, J.T. K. BREddam \& M. Ottesen: Isolation of carboxypeptidase $Y$ by affinity chromatography. Carlsberg Res. Commun 41, 1-14 (1976)

11. Morihara, K., T. OKa \& H. Tsuzuki: Semisynthesis of human insulin by trypsin-catalyzed replacement of Ala-B 30 by Thr in porcine insulin. Nature 280, 412-413 (1979)

12. TsuzuKI. H., T. OKa \& K. Morihara: Coupling between $\mathrm{Cbz}-\mathrm{Arg}-\mathrm{OH}$ and Leu-X catalyzed by trypsin and papain. J. Biochem. (Tokyo) 88, 669$675(1980)$ 